\title{
Arquitectura de la «Tradición Mito» en el valle medio del Santa: sitio «El Silencio»
}

Architecture de la «Tradition Mito » dans la moyenne vallée du Santa : site « El Silencio »

Architecture of the «Mito Tradition» in the Santa middle Valley: site «El Silencio»

\section{María Montoya Vera}

\section{OpenEdition}

\section{Journals}

Edición electrónica

URL: http://journals.openedition.org/bifea/3795

DOI: $10.4000 /$ bifea.3795

ISSN: 2076-5827

\section{Editor}

Institut Français d'Études Andines

\section{Edición impresa}

Fecha de publicación: 1 agosto 2007

Paginación: 199-220

ISSN: 0303-7495

\section{Referencia electrónica}

María Montoya Vera, « Arquitectura de la «Tradición Mito» en el valle medio del Santa: sitio «El Silencio» », Bulletin de l'Institut français d'études andines [En línea], 36 (2) | 2007, Publicado el 01 febrero 2008, consultado el 02 diciembre 2020. URL : http://journals.openedition.org/bifea/3795 ; DOI : https://doi.org/10.4000/bifea.3795

\section{(c) $(1) \odot$}

Les contenus du Bulletin de l'Institut français d'études andines sont mis à disposition selon les termes de la licence Creative Commons Attribution - Pas d'Utilisation Commerciale - Pas de Modification 4.0 International. 


\title{
Arquitectura de la «Tradición Mito» en el valle medio del Santa: sitio «El Silencio»*
}

\author{
María Montoya Vera**
}

\begin{abstract}
Resumen
Se da a conocer la presencia de estructuras arquitectónicas monumentales en el sitio El Silencio (valle medio del Santa), las mismas que se asimilan a la «Tradición Mito» definida para áreas propias de la sierra central. Por su ubicación geográfica El Silencio representa el caso más noroccidental en los Andes Centrales. Se presenta a su vez la correlación morfológico-arquitectónica de dos edificios de esta misma tradición presentes en el sitio. Asimismo, se plantea que el área en mención evidencia una nueva problemática relacionada al surgimiento y desarrollo de la arquitectura monumental, debido a la presencia de un «pozo circular hundido», considerado generalmente de tradición costeña, es decir, tanto la tradición serrana como la costeña convergen en el sitio El Silencio.
\end{abstract}

Palabras clave: Tradición Mito, El Silencio, Valle medio del Santa, estructuras arquitectónicas, Andes Centrales

\section{Architecture de la « Tradition Mito» dans la moyenne vallée du Santa : site « El Silencio»}

\section{Résumé}

Cet article étudie la présence de structures architecturales monumentales sur le site El Silencio (moyenne vallée du Santa) assimilées à la "Tradition Mito », définie pour les zones de la sierra centrale. De par sa situation géographique El Silencio constitue le site de la partie la plus nord-occidental des Andes Centrales. Ce texte rend compte également d'une correspondance morphologico-architecturale entre deux bâtiments de cette tradition, présents sur ce site. Cette zone fairait donc apparaitre une nouvelle problématique en ce qui concerne la compréhension du développement social dans les Andes, due en

* Los trabajos arqueológicos en el sitio El Silencio los realizamos entre 1988-1989, en el marco del Convenio entre la Universidad Nacional de Trujillo y el Proyecto de Rescate Arqueológico Chavimochic (PRACH) ejecutado por el Instituto Departamental de Cultura - La Libertad.

** Universidad Nacional de Trujillo. E-mail: marianectandra@hotmail.com 
outre à la présence d'un puits circulaire profond considéré comme caractéristique de la région côtière c'est-à-dire qu'aussi bien la tradition des Andes que celle de la côte coïncident sur le site El Silencio.

Mots clés : Tradition Mito, El Silencio, moyenne vallée du Santa, structures architecturales, Andes Centrales

\title{
Architecture of the «Mito Tradition» in the Santa middle Valley: site «El Silencio»
}

\begin{abstract}
Various monumental architectonic structures from the site of El Silencio in the middle valley of Santa are recognized as a part of the «Mito Tradition» defined for areas of the central highlands. Due to its geographic location, El Silencio represents the most north-west site of the Central Andes belong to this tradition. The architectonic correspondence of two buildings of the same tradition located on this site is demonstrated. This site proves that questions still remain about the understanding of the Andean social development within this period, particularly considering the presence of a deep sunken circular courtyard, a feature usually considered as belonging to a coastal tradition. Thus, the site El Silencio shares both the highland and coastal tradition.
\end{abstract}

Keys words: «Mito Tradition», El Silencio, Santa middle valley, architectonic structures, Central Andes

\section{LA TRADICIÓN ARQUITECTÓNICA «MITO»}

La Tradición Arquitectónica Mito debe su nombre al primer sitio arqueológico descubierto de esta tradición en el sitio de Kotosh (Huánuco), encontrada debajo de la primera ocupación con cerámica conocida como Kotosh Wairajirca (Izumi \& Terada, 1972). A esto se debe el nombre y no precisamente porque de allí parta el origen o difusión de esta tradición hacia otros sitios donde han sido halladas formas arquitectónicas similares, como las reportadas hasta ahora en sitios como La Galgada (Pallasca en Ancash, Grieder et al., 1988), Piruru (Tantamayo en Huánuco, Bonnier \& Rozemberg, 1987; Bonnier, 1997), etc. Agregamos a esta lista el sitio El Silencio (La Libertad) que en el presente artículo daremos a conocer a los investigadores que puedan estar interesados en este tema, a pesar de haber transcurrido 16 años desde su hallazgo (Uceda, 1988; Montoya, 1989).

El desarrollo de los centros ceremoniales complejos debió ser paralelo al surgimiento de una clase sacerdotal que controlaba los excedentes agrícolas (Lumbreras, 1981). Es así que en la zona entre Huánuco y el Callejón de Huaylas se han registrado estructuras arquitectónicas monumentales de la Tradición Mito. Estas formas similares que se presentan en diversos sitios de los Andes Centrales debieron tener algún tipo de relación entre sí. Diversos autores han emitido hipótesis al respecto (Bonnier \& Rozemberg, 1987; Fung, 1988) considerando que estas evidencias arquitectónicas tempranas en diversos sitios de los Andes Centrales constituyen una tradición particular en esta área.

A su vez Burger \& Salazar Burger (1980) plantean, en relación al parentesco entre los edificios de la Tradición Mito registrados en Huaricoto, Kotosh, La Galgada, etc., que la tecnología constructiva, labor invertida, variaciones en la orientación (es decir, las diferencias relativas que tienen estos sitios) se debería a la existencia de una jerarquía de sitios rituales en el área de la sierra central. Pero, de hecho, estuvieron ligadas y dedicadas a variantes de una misma ideología con rituales similares; ellos establecen por eso el término de «Tradición Religiosa Kotosh». 
La presencia de fogones es considerada como la característica principal pues son elementos siempre presentes en las formas arquitectónicas de la Tradición Mito. Precisamente el fuego, al parecer, tuvo un rol preponderante en el surgimiento de gente especializada que dirigiría las ceremonias y cultos nacientes, expresado en un tipo similar de comportamiento cultural en el que lo simbólico y religioso tuvo una mayor importancia. Precisamente esta ideología se expresa materialmente en la Tradición Arquitectónica Mito.

Bonnier (1997) compara y contrasta las evidencias arquitectónicas reportadas en sitios contemporáneos como La Galgada, Piruru, Shillacoto, Huaricoto, tomando como base las amplias excavaciones realizadas por el equipo japonés de Izumi y Terada en los años 1960 en Kotosh. Considera que la «religión Mito» floreció durante la segunda mitad del periodo Precerámico Tardío y unificó el área del Santa, el Alto Marañón y el Alto Huallaga en los Andes norcentrales. Plantea la existencia de una arquitectura Pre-Mito caracterizada por el piso plano del altar principal y el uso de tierra roja como material de construcción en estos edificios. Estos rasgos son evidenciados en Piruru y Kotosh por Bonnier (1997). Esta arquitectura fue complejizándose paulatinamente al incluir progresivamente dos niveles (usando los términos de pericausto y epicausto) en estos altares (fase Mito I en Kotosh, La Galgada) los que, al inicio, presentarían poca altura entre el desnivel de los pisos. A esta evolución arquitectónica luego se agregarían pequeños nichos en el muro perimetral de estos edificios (Kotosh), culminando este proceso en el Templo de los Nichitos etapa II (subfases Mito IIIc, IIId).

Después del periodo de ocupación Mito en muchos de estos sitios (Kotosh, Shillacoto, Wayrajirca, Piruru, La Galgada, Huaricoto) son reportadas ocupaciones asociadas a cerámica del Periodo Inicial, desapareciendo la Tradición Mito paralelamente a esto. En el presente artículo presentaremos las evidencias de que algo similar ocurre para el sitio El Silencio. Es cierto que nos queda pendiente realizar una correlación más exhaustiva sobre los contextos de aparición de esta cerámica inicial entre todos los sitios luego de ocupaciones del Precerámico de la fase Mito, para definir la difusión u originalidad de los mismos en sus áreas geográficas. Para el sitio El Silencio hemos podido evidenciar que se trataba de gente que ya tenía conocimientos de producción alfarera y que provenían de una tradición cultural común, lo que implica que, luego de la ocupación Temprana, debió existir un abandono del sitio hasta la llegada de gente con conocimiento alfarero. Este abandono debió haber sido producto de algún cambio significativo entre la gente que afluía al centro ceremonial Temprano de El Silencio, aspecto que tampoco está bien definido en general para otros sitios contemporáneos.

Bonavia pone en duda la hipótesis según la cual hablar de «Mito» significa necesariamente referirse al periodo Precerámico. Se basa en la presencia de estratos supuestamente Mito en Shillacoto de donde procedería una vasija cuya foto publica y describe como

«Recipiente de cerámica de cuerpo globular con dos picos unidos por un asa puente y decorada con incisiones. Kotosh-Mito. ca. 2000 años a.C. (Shillacoto). 16 cm X 24 cm» (Bonavia, 1994: foto 3).

De ahí se considera que el sitio de Kotosh, en estratos Mito, no pertenecería al periodo Precerámico.

Debemos mencionar que la presencia de sitios monumentales tempranos en los que no ha sido registrada cerámica no necesariamente se ubicarían en el Periodo Precerámico. Al respecto los esposos Pozorski (1999) introducen el término Acerámico, a diferencia del término Precerámico, cuyo uso se encuentra restringido a sociedades que, si bien tuvieron un desarrollo notable en la arquitectura, aún no habían desarrollado la tecnología cerámica. El término Acerámico surge a raíz de que existen casos notorios de sitios en la costa norte y central peruana (Salinas de Chao, Alto Salaverry, El Paraíso, y parte de la ocupación del sitio de Huaynuná que, a su vez, presenta algunos componentes arquitectónicos de la Tradición Arquitectónica Mito por lo que plantean que «representa la comunicación costa-sierra») en los que si bien no ha sido encontrada cerámica asociada, al correlacionar los fechados obtenidos, éstos resultan contemporáneos a 
otros sitios monumentales pero ya del Periodo Inicial (o Formativo Temprano), en los que sí ha sido registrado el uso de cerámica (La Florida y Garagay).

Los Pozorski consideran poco probable que los fechados sean erróneos o muy escasos, ya que son varios y de diferentes sitios. Más bien sugieren que estos grupos sin cerámica fueron tomando contacto con los que ya tenían conocimiento de cerámica, deviniendo luego en un uso generalizado de ésta.

Es de entrever sin embargo que así como queda pendiente una discusión más exhaustiva sobre por qué asentamientos contemporáneos próximos hayan tenido un comportamiento tan disímil en relación al uso o no de la cerámica, así también y a pesar de las investigaciones realizadas a la fecha, queda aún por dilucidarse el origen y las implicancias en el desarrollo cultural andino durante el periodo temprano, de la particular Tradición Arquitectónica Mito.

\section{UBICACIÓN Y DESCRIPCIÓN DEL SITIO EL SILENCIO}

Políticamente se ubica en la Hacienda Suchimancillo, distrito de Virú, provincia de Trujillo, departamento de La Libertad, en la margen derecha del río Santa, sobre el cono aluvial de la Quebrada El Silencio, en el valle medio del Santa. El sitio está caracterizado ecológicamente dentro de una Formación de Desierto Pre-Montano, de clima del tipo per-árido con temperatura semi-cálida de un promedio de $22^{\circ} \mathrm{C}$ (ONERN, 1972). Se ubica a $78^{\circ} 19^{\prime}$ de longitud Oeste y a $8^{\circ} 39^{\prime}$ de latitud Sur, y a una altura de $415 \mathrm{msnm}$. Se encuentra a una distancia de $50 \mathrm{~km}$ en relación a la línea playera, y a 4,5 km de la confluencia entre los ríos Santa y Tablachaca (fig. 1).

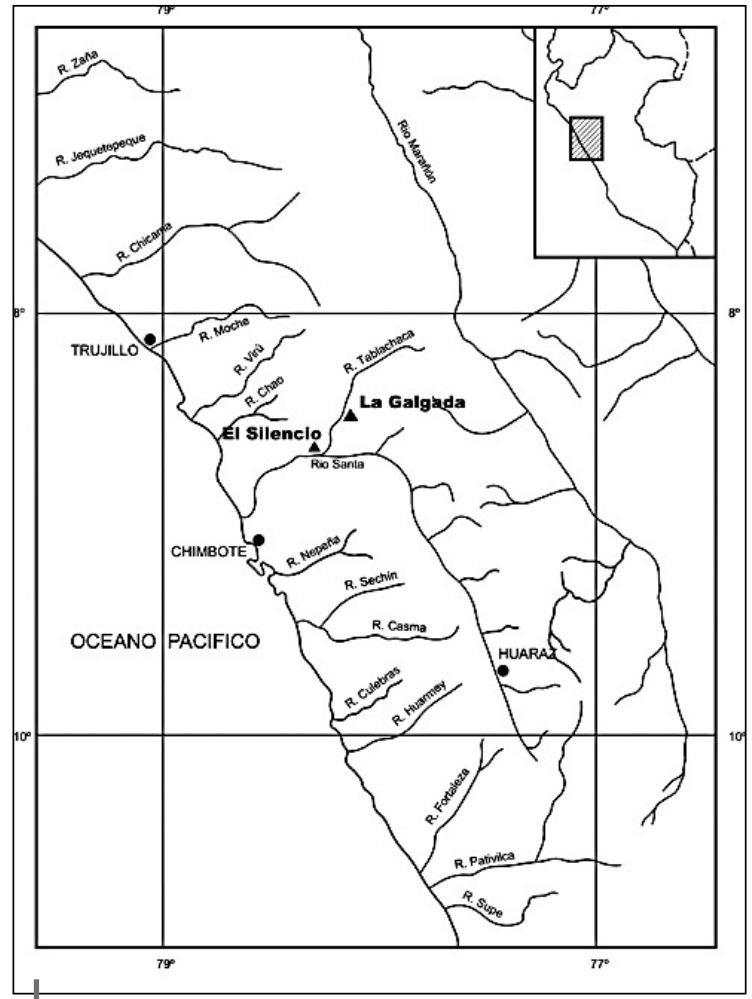

Figura 1 - Ubicación del sitio El Silencio (VS 103-6) en el valle medio del Santa
Geomorfológicamente, presenta tres terrazas aluviales (originadas por el estrechamiento en el cauce del río Santa) que se extienden de Este a Oeste, hallándose flanqueado por el cerro Huacate al Norte (de consistencia granítica, por ende fracturable) y por el Sur con el borde del barranco que da hacia el río Santa. En la parte alta del cerro Huacate existen pequeñas quebradas que al bajar se extienden en forma de abanico sobre la terraza alta, cubriendo el mismo con materiales detríticos gruesos y finos provenientes de los derrames de este cerro. Las estructuras arquitectónicas más importantes del sitio se ubican sobre la terraza alta (fig. 2).

El sitio fue signado por el Catastro de Sitios Arqueológicos del INC/LL como VS 103: 6 (Uceda et al., 1988); se ubica en el área de confluencia de la Quebrada El Silencio, específicamente entre las faldas del cerro Huacate y el río Santa, sobre una angosta faja de terraza aluvial que se eleva a $25 \mathrm{~m}$ sobre el nivel promedio del cauce del río y a una distancia del mismo, de aproximadamente 60 a $80 \mathrm{~m}$. Tiene una extensión aproximada de 600 m en dirección E-W y 250 m de N-S. 


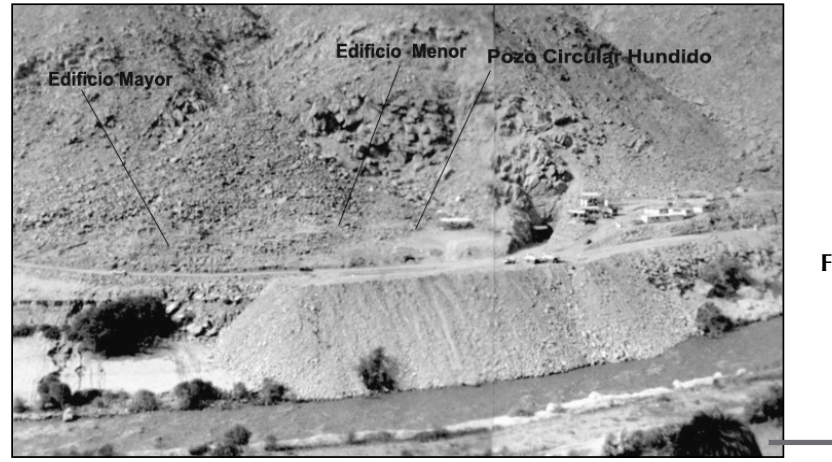

Figura 2 - Vista sur-norte (desde margen izquierda del río Santa)

Se observa el derrame de material detrítico proveniente del cerro Huacate sobre la estrecha terraza aluvial donde está ubicado el sitio arqueológico. Al extremo derecho de la foto se puede ver la salida del túnel aductor del proyecto Chavimochic

El grado de deterioro estuvo al parecer determinado mayormente por el acarreamiento de piedras de la parte alta del cerro Huacate, apreciándose además escombramiento de piedras de los muros, mezcladas con arena eólica, algunos pozos de huaquero, además de la construcción de una carretera afirmada que cortó por su lado sur el sitio, disturbando el área de terrazas agrícolas (fig. 2).

Se ingresa al sitio por una antigua trocha carrozable ubicada hacia el lado este de la carretera Panamericana Norte ( $\mathrm{km}$ 481-482), que fue realizada por la Corporación del Santa para los inicios de la irrigación Chavimochic, la cual estuvo deteriorada durante muchos años por deslizamientos de tierra, etc. Posteriormente este mismo tramo fue aprovechado y habilitado para la puesta en marcha del Proyecto Chavimochic. Esta carretera llega hasta el mismo sitio El Silencio, pasando por Tanguche y Pampa Blanca, hasta Ilegar a Suchimancillo. Actualmente el sitio prácticamente ha desaparecido, afectado por la construcción del canal de irrigación Chavimochic.

\section{SECTORIZACIÓN}

La sectorización fue realizada por el PRACH tomando en cuenta la distribución espacial de las estructuras arquitectónicas de superficie (fig. 3), las mismas que evidenciaban fragmentería cerámica asociada al estilo cultural Recuay, cronología que fue confirmada por las excavaciones realizadas al recuperarse este mismo estilo cerámico en contextos seguros en todos los tres sectores donde el PRACH realizó excavaciones.

\section{1. Sector 1}

Ubicado sobre la terraza aluvial, en la parte baja y al sur del cerro Huacate, reportó estructuras arquitectónicas, las que fueron subsectorizadas en:

- Edificio Mayor (fig. 4): edificio administrativo del periodo Recuay, construido con piedras grandes y argamasa de barro, sobre un montículo artificial; luego de las excavaciones se definió que estaba construido sobre un edificio monumental temprano. Hacia el Este limita con una estrecha quebrada de unos $9 \mathrm{~m}$ de ancho y tiene un desnivel de $3 \mathrm{~m}$ aproximadamente, separándolo del Edificio Menor.

- Edificio Menor: fue construido sobre un montículo natural, mostraba aterrazamientos hacia sus lados oeste y sur. Sobre este montículo se evidenciaban en superficie varios recintos con muros de piedra, de planta irregular, al interior de algunos de ellos fueron reportados batanes con huellas de desgaste. Por la arquitectura y el material cerámico recuperado corresponde a recintos habitacionales Recuay. Luego de las excavaciones se definió que bajo 


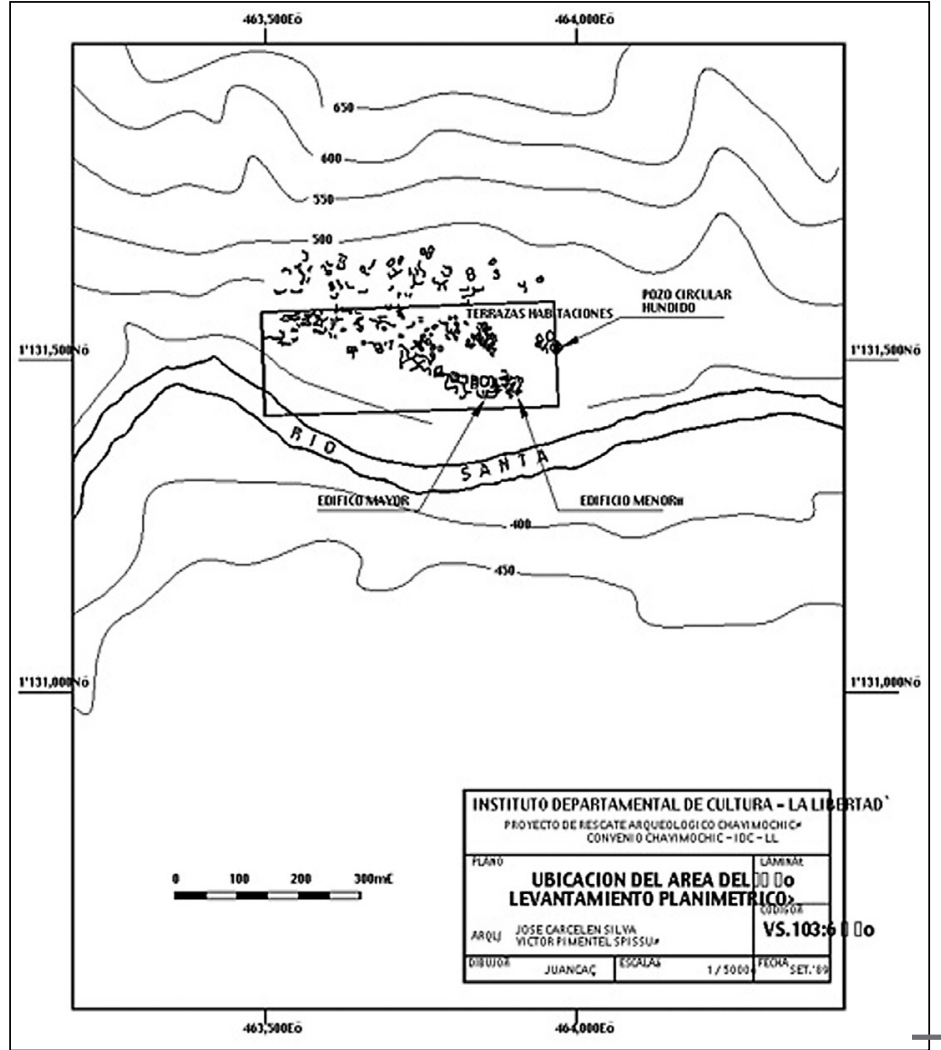

Figura 3 - Ubicación y áreas sectorizadas del sitio VS 103-6 en levantamiento planimétrico

estas construcciones habían dos ocupaciones anteriores: una asociada a cerámica del Periodo Inicial, y otra aún más antigua asociada a arquitectura monumental temprana (fig. 5), relativamente similar morfológicamente pero de dimensiones menores que el edificio monumental temprano en el Edificio Mayor.

- Pozo circular hundido: ubicado a $80 \mathrm{~m}$ hacia el noreste del Edificio Menor. Esta estructura tiene $18 \mathrm{~m}$ de diámetro y el piso a $2 \mathrm{~m}$ del nivel de la cabecera del pozo, fue reportado un acceso con cuatro escalones (fue excavada parcialmente por el PRACH).

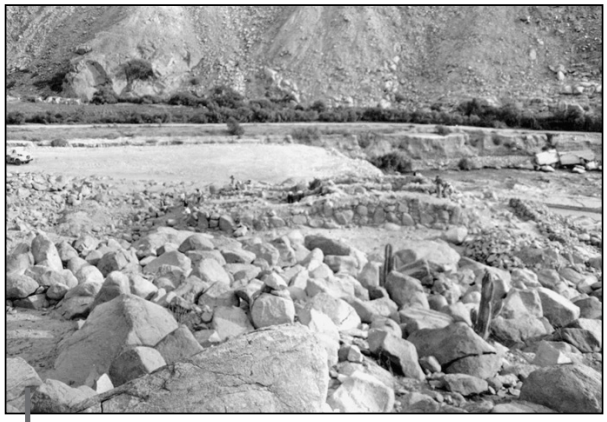

Figura 4 - Vista norte-sur del subsector Edificio Mayor

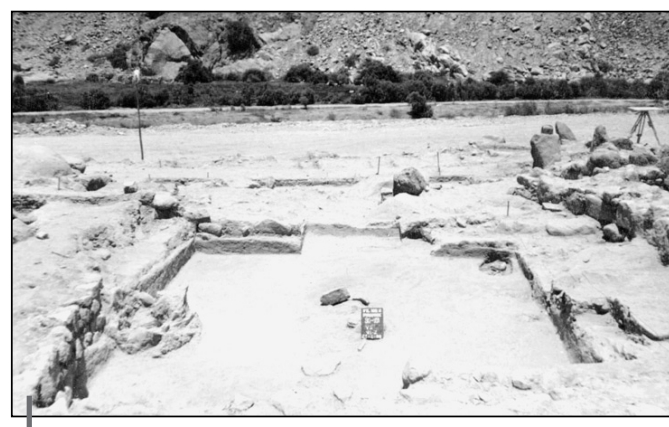

Figura 5 - Vista norte-sur del subsector Edificio Menor 


\section{2. Sector 2}

Se halla ubicado en las laderas del cerro Huacate, al norte del sector 1 . Se encuentra conformado por terrazas habitacionales, asociadas a contextos de ocupación Recuay. Estas terrazas fueron adaptadas por muros de contención luego de nivelar el terreno escarpado y pedregoso propio del cerro.

\section{3. Sector 3}

Este sector se ubica en la parte más baja del sitio al lado sur y suroeste de los sectores 1 y 2 . Está conformado por terrazas agrícolas, las que eran irrigadas por canaletas de derivación que se proyectaban desde un canal principal que cruza de este a oeste el sitio.

\section{EL EDIFICIO MENOR}

\section{1. Excavaciones y estratigrafía}

La ubicación del área a excavar estuvo determinada por la presencia en superficie de los muros del recinto signado como $\mathrm{H} 8$, pero básicamente también por la presencia de una hilera de piedras casi al ras de la superficie. Pareciera que esta hilera no guardaba relación con los muros del recinto H8. Para dilucidar si se asociaban o no se propuso la realización de dos trincheras paralelas (de $1 \times 2 \mathrm{~m}$ y $2 \times 4 \mathrm{~m}$ ), pero separadas por un testigo de 0,50 $\mathrm{m}$ de ancho, el cual fue dejado para correlacionar la estratigrafía (fig. 6) entre ambas excavaciones. Las excavaciones estuvieron así orientadas, tanto a definir la función del recinto H8, como la asociación que pudiera existir entre ambos tipos de arquitectura.

La excavación se hizo por capas naturales, las que fueron definiéndose por su naturaleza, espesor, contenido, elementos arquitectónicos (la definición de capa se halla referido tanto a rellenos, escombros, capas de ocupación, como también a pisos y a superficies de uso o apisonamiento).

El análisis estratigráfico se hizo básicamente mediante la definición de la naturaleza de cada capa arqueológica en relación a un determinado vestigio arquitectónico y la correlación de las evidencias culturales con respecto a la capa de procedencia a la cual se hallaban asociados, para así (luego de establecer su naturaleza) ubicarlos en relación a una determinada fase ocupacional y, por ende, cronológica. Este estudio estuvo orientado a establecer los acontecimientos tanto culturales como naturales con el fin de poder obtener una reconstrucción aproximada de la historia del sitio.

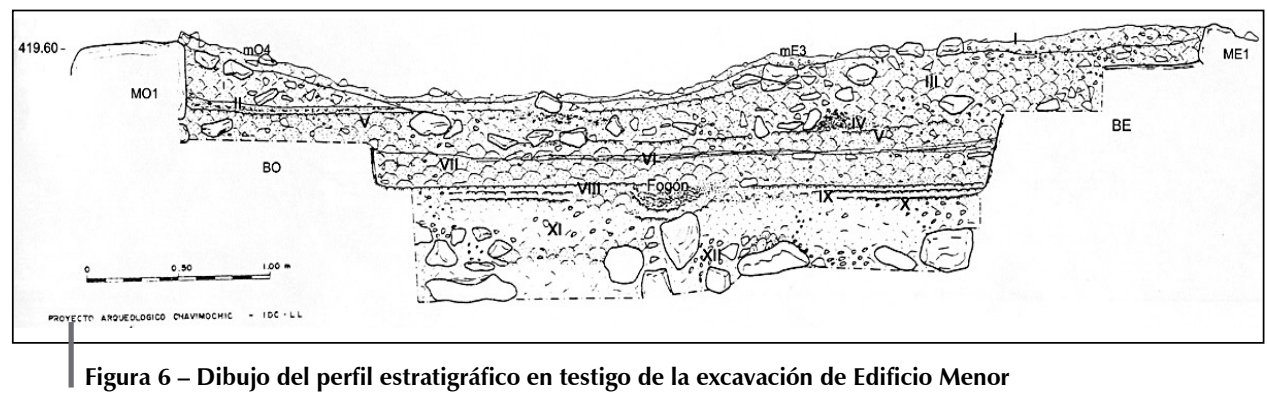




\section{2. Descripción de perfiles estratigráficos}

El perfil norte del testigo dejado en la unidad V Z (cuadros 89-99) y VI Z (cuadros 80-84) nos presentó una visión clara de su estratificación (fig. 6), es decir de la superposición de las diversas capas y estructuras arquitectónicas relacionadas tanto a la ocupación sin cerámica asociada a la arquitectura monumental Temprana, como a la ocupación de Cerámica Inicial, así como del Periodo Intermedio Temprano, identificadas en el sitio.

El perfil que describiremos a continuación presenta las etapas de formación desde el suelo estéril hasta la superficie del área excavada, que llegó a alcanzar entre 80 a $100 \mathrm{~cm}$ de espesor.

\section{2. 1. Perfil norte}

Muestra primeramente una capa de acondicionamiento de la superficie natural (capa XII). En esta se observan piedras grandes y medianas como base y luego arena gruesa y piedrecillas (capa $\mathrm{XI}$ ) para nivelar el terreno de construcción. Continúa una superposición de tres pisos conformado por las capas X, IX y VIII respectivamente. La capa X (que funcionaría como base del enlucido posterior) está constituida por una tierra compacta de color blanquecino. La capa IX a manera de enlucido, está constituida por una tierra fina amarillenta de textura muy suave. La capa VIII es una tierra gris semicompacta que debió a su vez enlucir internamente la estructura arquitectónica temprana, entre los muros MO1 y ME1; un fogón central se evidencia al interno de esta estructura arquitectónica (pero no se puede definir claramente su forma original por haber estado alterado con la intrusión del entierro de un párvulo E1). Sobre este piso gris (capa VIII) no se hallaron huellas de ocupación, sino una especie de relleno (capa VII) consistente en tierra compacta con arena gruesa y piedras pequeñas (sin evidenciar material cultural). En el perfil hacia el lado oeste, en esta última capa, se hallan piedras pequeñas donde se evidenciaría luego el entierro E2 que rompe esta capa y que cubrieron con piedras pequeñas. Luego, conformando la capa $\mathrm{VI}$, se aprecia una tierra semicompacta de poco espesor y de color grisáceo conteniendo poca ceniza y carbón; hacia el lado este, al pie de la banqueta, se halla una acumulación de sedimentos en pequeñas láminas sucesivas. Las capas VI y VII se hallan circunscritas al espacio cuadrangular hundido entre las banquetas oeste y este.

Sobre la capa VI se asienta una tierra marrón clara con sedimentos y piedras medianas que son acumuladas al parecer por el abandono del sitio y la sucesiva destrucción natural arquitectónica temprana. La capa $V$ se halla distribuida entre el paramento de la banqueta este (la cual está casi completa) y sobre la banqueta oeste (hallándose aquí ya destruida) por lo que se puede plantear que la banqueta oeste tuvo la misma altura y configuración que la del este.

Superponiéndose a esta última capa se observa una tierra concentrada hacia el lado este (capa IV) consistente en tierra gris con carbón y ceniza, materiales que se hallan asociados a material malacológico y fragmentos de cerámica de vasijas cerradas sin cuello asignados al Periodo Inicial. Este no es un piso (definido así como elemento arquitectónico) sino una superficie de uso o apisonamiento, en el que la capa $V$ sería acondicionada o nivelada para ser habitada.

Luego se observa, en la capa III, tierra concentrada mayormente hacia el este y centro de la estructura arquitectónica temprana (ME1 y hasta donde se pierde bajo muro mE3) conteniendo tierra compacta grisácea, piedras medianas y grandes, conformando una acumulación de escombros que se observa desde el muro perimetral este de la estructura temprana y que debió llegar probablemente hasta el muro oeste de la misma (al igual que la capa IV). Sin embargo, debido a una intrusión (de la capa II sobre la capa III y IV), esta capa está rota y alterada al asentarse la ocupación tardía asociada a una ocupación del Periodo Intermedio Temprano entre los muros MO1 y mE3, conformando un nivel de uso o apisonamiento hacia el lado oeste dentro de la estructura arquitectónica temprana y reutilizando el muro oeste del mismo. La capa II está conformada por una superficie de uso (no piso propiamente dicho) en la cual se halla tierra semicompacta gris oscura, con quemas y concentración de ceniza, carbón, restos 
vegetales y fragmentos de cerámica asociada a una ocupación del Periodo Intermedio Temprano, mayormente hacia el lado oeste (junto al paramento del muro MO1) y al centro donde se observa una acumulación de piedras medianas con carbón. Funcionaría como fogón asociado a esta ocupación durante la cual se construyó el muro hacia el lado central este mE3 que rompe y está asociado sobre la capa III.

En la capa I, se observa una mayor concentración hacia el lado oeste junto al paramento del muro perimetral temprano (MO1), donde se hallan piedras medianas conformando el basamento del muro que se evidenciaba en la capa superficial (mO4) restringiendo así el área del anterior recinto (entre el MO1 y mE3), y conformando ya el recinto H8 de superficie (asociado también a la superficie de uso de la capa II). La capa I está conformada además por tierra semicompacta beige claro con sedimento y grava y tiene una mayor concentración hacia el lado oeste que al centro. Como última capa, en el perfil, se halla la de superficie, que se muestra a desnivel en lo que es la parte interna del recinto superficial $(\mathrm{mO} 4$ y $\mathrm{mE} 3)$ y que consiste en tierra sedimentada con piedras pequeñas dispersas sobre toda el área.

\section{3. Correlaciones internas}

El análisis de la estratigrafía de las áreas excavadas ha permitido distinguir periodos y momentos ocupacionales asociados a determinados rasgos o elementos arquitectónicos, que en contextos asociados a determinados niveles estratigráficos (rellenos, escombros, pisos) y según su contenido cultural, nos van definiendo también la posible función a la que fueron destinados. Esto permitió establecer correlaciones internas asociadas a determinado momento cultural y dentro de periodos mayores.

Podemos evidenciar que desde la capa III hacia arriba la estratigrafía se vuelve más compleja debido a que tanto en capas asociadas a una ocupación del Periodo Inicial como en sus posteriores escombros que la cubrían, se halla una intrusión de otras capas producidas por una ocupación asociada al Periodo Intermedio Temprano (recinto H8) las que rompen las capas anteriores para poder habitar en el área.

Se han podido aislar básicamente dos periodos, uno que pertenece a una ocupación sin cerámica, y el otro al de una ocupación ya con cerámica.

\section{3. 1. Ocupación sin cerámica}

En esta se distinguen dos momentos ocupacionales:

a. Primera fase

Está representada por una estructura arquitectónica de planta cuadrada con esquinas redondeadas $(7 \times 6,60 \mathrm{~m})$, con un espacio cuadrangular hundido $(3,30 \times 3,20 \mathrm{~m})$ al interior y en la que, al centro, se halla un fogón circular (0,60 m de diámetro). El acceso al recinto está orientado hacia el sur con un vano de 1,10 m de ancho. Los muros (M1) externos (0,60 m) son de mampostería de piedra con mortero de barro, de doble paramento, con doble reboque tanto interno como externo y de color, uno blanquecino al que se le superpone otro de color grisáceo revistiendo los paramentos de muros. El espacio cuadrangular hundido que se halla al interior está relacionado a los muros exteriores o perimetrales por medio de banquetas que lo rodean $(0,80$ a $1 \mathrm{~m}$ de ancho y a $0,60 \mathrm{~m}$ de altura sobre el piso interior).

Sobre la base o piso original de la estructura se hallan dos pisos más. El original es de color blanquecino (capa $\mathrm{X}$ ) y asociado por media caña a los muros de las banquetas que lo rodean. El fogón central evidencia un enlucido, aunque su estado de conservación es muy deteriorado, lo mismo que el piso original donde se observan además algunos grumos grisáceos de tierra arcillosa. Sobre este se halla un segundo piso (capa IX), muy destruido de color amarillento que 
se une prácticamente al reboque blanquecino de los muros circundantes de las banquetas. En el fogón central se evidencia en su interior, tierra compacta grisácea con quemas. Un tercer piso (capa VIII) se halla casi inmediatamente sobre el piso interior amarillento; presenta una coloración gris hallándose en buen estado de conservación, al centro se evidencia el fogón delimitado por piedras y con restos de tierra compacta, pero alterado por la presencia de un entierro de infante (el entierro estaba flexionado en posición decúbito lateral izquierdo, orientado de SW-NE, asociado a material orgánico y un fragmento de cuarzo).

Sobre el último piso grisáceo (capa VIII) no se halló ningún material cultural, estando este completamente limpio y cubierto por un relleno (capa VII) que tiene aproximadamente entre 0,15 y $0,20 \mathrm{~m}$ de espesor y cubre íntegramente el espacio cuadrangular interno. El relleno está limpio de material cultural y tiene un contenido de tierra compacta marrón clara con arena gruesa y piedrecillas. En este sentido, si se considera que el entierro (E1) de infante hallado dentro del fogón central de esta estructura arquitectónica temprana es posterior al relleno (capa VII) entonces debiera haberse hallado cubierto también el fogón por este relleno, aspecto que no se evidenció; al parecer lo más probable es que el entierro fuera colocado primero dentro del fogón, el cual sería usado como una especie de urna, y cubierto posteriormente por piedras pequeñas. De esta forma el relleno que cubriría casi homogéneamente el espacio cuadrangular interno, necesariamente tendría que cubrir las piedras sobre el entierro.

\section{b. Segunda Fase (capas VI y VII)}

Este momento de ocupación al parecer ocurre después que el sitio haya sido abandonado y colocado el relleno, dado que se evidencia una intrusión de otra gente. Esto está evidenciado por el hallazgo de cuatro entierros que rompen el piso y banquetas de la estructura cuadrangular temprana, reflejando que este ya había perdido su función original. Los entierros tienen la característica de haber sido colocados en pequeñas fosas rellenándolas, luego de colocar los cadáveres, con tierra marrón clara suelta y cubriéndolos con piedras pequeñas. De los cuatro entierros solo uno pertenece a una edad promedio de adulto y los otros son de párvulos, la orientación general de estos es de SW-NE, en posición fetal; solo el adulto (E5) está orientado de N-S y en posición extendida. Todos los entierros estaban asociados a material orgánico y fragmentos de carbón. En un entierro de párvulo (E2) se halló un mate pequeño, y en otro (E5) una lasca de cristal de roca. Todos están dentro del espacio cuadrangular hundido al interior de la estructura temprana.

Este momento ocupacional, a pesar de haber perdido ya su función original, reflejaría aún cierta influencia religiosa entre la gente que enterró los cadáveres, aunque intruyan parte de la estructura arquitectónica temprana. Por lo demás no se evidencia ocupación propiamente doméstica sino como lugar de entierro, siendo notable la ausencia de cerámica asociada a los entierros, pudiendo asimilarse también este momento ocupacional dentro del periodo Precerámico Tardío.

\section{3. 2. Ocupación con cerámica}

Para la ocupación con cerámica se distinguen claramente dos momentos ocupacionales:

\section{a. Primera Fase}

La capa de ocupación III evidencia escombros del muro (mE2) de la banqueta noreste que, al parecer, fue reconstruido por otra gente (IV), colocando piedras como paramento, elevando así el muro (BE) anterior que se hallaba en parte destruido, pero éste ya sin reboque. La presencia de capas de sedimentos, grumos grisáceos y escombros nos indicaría un abandono del sitio. Esta ocupación eventual (capa IV), siempre dentro del espacio cuadrangular interno de la estructura temprana, construye un fogón circular al lado norte, bien delimitado por piedras algo planas (este fogón intruye en las capas $\mathrm{V}$ y VI rompiendo la banqueta norte de la estructura temprana). 
El fogón estuvo asociado a un nivel de apisonamiento o superficie de ocupación (capa IV y V) conteniendo tierra semicompacta gris con ceniza y un muro ( $\mathrm{mO} 2)$ paralelo a la banqueta noreste que restringe en cierto modo el área del fogón circular norte. Este fogón tuvo un contenido abundante de tierra gris-rojiza, carbón y ceniza sobre la cual se halló una concentración de cerámica diagnóstica asociada a tipos correspondientes al periodo Inicial así como también a restos de material malacológico.

Este momento eventual de ocupación, ya con cerámica, refleja un uso doméstico en el sitio, hecho por otra gente que intruye, rompiendo la banqueta norte para construir el fogón, reconstruyendo también el muro de la banqueta este pero ya sin reboque.

\section{b. Segunda fase}

Este momento ocupacional se evidencia, siempre dentro de la estructura arquitectónica temprana, pero restringiéndose hacia su lado suroeste. A su vez esta ocupación intruye las capas III, IV y V (alterando en parte también la ocupación asociada a cerámica del Periodo Inicial que debió hallarse en la capa IV si se considera que éste se extendería hacia el lado oeste). Esta ocupación se halla asociada a un recinto de forma semirectángular cuyos muros $(\mathrm{m} 3)$ son de doble paramento y mampostería ordinaria, su muro norte $(\mathrm{mN} 3)$ se adosa al muro (MO1) perimetral suroeste de la estructura arquitectónica temprana. Asociado a este recinto tardío se halla una superposición de ocupación (capa II) conteniendo ceniza, carbón, restos vegetales, malacológicos, fragmentos de cerámica, torteros para hilado; una mayor concentración de estos materiales se halla hacia el lado oeste junto al paramento del muro perimetral de la estructura arquitectónica temprana que es aquí reutilizado y cuyo muro, ya sin reboque, tiene manchas de hollín por las quemas producidas.

Al parecer se realiza luego una nueva restricción en esta área y que corresponde propiamente al recinto que se evidenciaba en superficie signado como $\mathrm{H} 8$, pues colocan piedras medianas (como basamento de muro) sobre el área de quemas al oeste, pudiendo así dar estabilidad a piedras más grandes que conformarían el muro oeste (mO4); hacia los lados norte y este se elevarían los muros (m3) sobre la base de los ya existentes del anterior recinto. Hacia el lado sur el área se halla muy erosionada y no pudo ser muy bien definida.

De las características de estos últimos momentos ocupacionales se puede deducir la existencia de una función doméstica restringida a áreas ya delimitadas por recintos, asociados a una ocupación del Periodo Intermedio Temprano.

\section{SECUENCIA OCUPACIONAL EN EL EDIFICIO MENOR}

Realizamos las excavaciones específicamente en la parte norcentral del subsector Edificio Menor del sector 1, y reportamos la siguiente secuencia ocupacional, que vamos a describir a continuación de manera muy escueta puesto que no es el tema principal del presente artículo (para información más detallada véase Montoya, 1989):

\section{1. Arquitectura Monumental Temprana}

Si bien no ha sido realizado el análisis radiocarbónico en el sitio El Silencio, proponemos que la ocupación cultural en el sitio se iniciaría cronológicamente desde el periodo Precerámico Tardío, esto en la medida que se halla estratigráficamente sobre suelo estéril. Está asociado a contextos sin cerámica, y en menor grado por las características morfológico-arquitectónicas (que la asimila a los templos de la Tradición Mito ubicados por lo general en el Precerámico Tardío), lo cual determina hasta cierto punto su ubicación en este periodo cultural, con una función de carácter público-religioso. Debemos mencionar que el PRACH, si bien inicialmente 
realizó excavaciones en trinchera, posteriormente los edificios tempranos Mayor y Menor fueron definidos íntegramente por excavaciones en área, y no se recuperó fragmento cerámico alguno. Sus pisos fueron encontrados limpios, cubriéndose luego ese espacio con un relleno también limpio exprofesamente. Sin embargo es significativa la ausencia de cerámica en contextos asociados a ambos edificios, por lo que no podríamos tampoco descartar de plano que dichos edificios no pertenezcan al período Precerámico Tardío.

Sin embargo otra hipótesis nos hace replantear esta posibilidad pero tampoco nos permite afirmar categóricamente que el sitio pertenece al periodo Precerámico Tardío. Esto surge a raíz de encontrar los pisos limpios, ya que su presencia puede deberse a algún ritual, en el cual de hecho si existió alguna evidencia de cerámica ésta fue retirada al igual que todos los otros artefactos que pudieran haberse depositado en el edificio en algún momento, edificios que por la connotación ritual que tienen generalmente son encontrados limpios previo al ritual de entierro.

El edificio fue posteriormente reutilizado como área de entierros humanos (entre ellos tres son niños menores de 2 años y un adulto), los cuales fueron colocados dentro de fosas individuales en el espacio cuadrangular hundido de la estructura monumental. Al momento de los entierros, el sitio ya había perdido su funcionalidad original por lo que, al intruir, rompieron parte de los paramentos, piso y relleno de este edificio.

\section{2. Periodo Inicial}

Posteriormente se evidencian ocupaciones ya con cerámica, las que por sus características (Montoya, 1989) muestran cierta correspondencia temporal con los sitios de Guañape, Ancón y Las Haldas, en base a componentes como: pasta, formas y algunas de las decoraciones, por lo que estarían asociadas a grupos culturales del Periodo Inicial. Esta ocupación reflejó diversidad de actividades de subsistencia, por el hallazgo de material malacológico (Donax obesulus, Aulaconya ater, Choromytilus chorus) que proceden de áreas ecológicas diferentes a las del sitio, lo que debió involucrar un determinado tipo de relaciones con grupos más cercanos al litoral. Sin embargo, esta ocupación representa un momento eventual en todo el sitio en general, dado que también a pesar de la amplitud de las excavaciones realizadas por el PRACH, las únicas evidencias para este periodo (aparte de las anteriormente mencionadas) fueron reportadas hacia el lado oeste de mi área de excavación (Edificio Menor) donde personal del PRACH recuperó un entierro humano asociado a variado material vegetal (maní, palta, calabaza, zapallo, etc.) entre otras ofrendas, entre las cuales destaca una figurina de cerámica representando a un hombrecito con caperuza (en la cual se aprecian incisiones lineales verticales) en posición sentada, y una pequeña ollita de cerámica con incisiones lineales en la parte externa. Estos objetos, por su morfología y características particulares, reflejan cierta familiaridad también con sitios tempranos como la figurina y el mate con incisiones hallados en Huaca Prieta por Bird (1948).

\section{3. Periodo Intermedio Temprano}

En un tercer y último periodo se ubican las estructuras arquitectónicas que se evidenciaban en superficie, las cuales tenían las características de recintos habitacionales, aspecto que fue confirmado por las excavaciones que realizamos en el recinto signado como H8 (asociado a contextos con cerámica Recuay). Posteriormente realizamos correlaciones entre $\mathrm{H} 8$ y los contextos (asociado también a fragmentos Recuay) recuperados por otros integrantes del PRACH en varios recintos habitacionales excavados tanto en el sector Edificio Menor (Montoya, 1989), como en los recintos ubicados en las terrazas de la ladera Sur del cerro Huacate (Montoya, 1989), los mismos que formaban parte de todo el asentamiento Recuay definido por el PRACH en El Silencio, conjuntamente con el edificio monumental de carácter administrativo ubicado en el Edificio Mayor y los canales y las terrazas agrícolas. 


\section{ARQUITECTURA MONUMENTAL TEMPRANA EN EL EDIFICIO MENOR}

Desearíamos dejar en claro que nuestra excavación fue realizada exclusivamente en el subsector Edificio Menor. Ya en el ítem precedente hemos explicado la secuencia ocupacional que reportáramos en el mismo; para mayor amplitud al respecto se debería consultar el informe final que presentamos en 1989 a la Universidad Nacional de Trujillo. En cuanto al Edificio Mayor, en el cual no excavé directamente sino solo participé como observadora eventual dada la proximidad entre ambos edificios, y que fueron excavados al mismo tiempo por el PRACH entre fines de 1988 y mediados de 1989, los informes hechos por los arqueólogos que participamos en dicho proyecto y que presentamos a fines de 1989 tanto al director del PRACH (en ese entonces el Dr. Santiago Uceda) como al arqueólogo residente (Lic. José Carcelén S.) pueden ser consultados en el Instituto Regional de Cultura de La Libertad en la ciudad de Trujillo.

En otro aspecto, también quisiéramos mencionar que hemos hecho uso de información proporcionada amablemente por el PRACH en ese entonces (1989) en lo referente a informes de campo, planos, dibujos, registros de excavación, fotografías, etc., con los que hemos podido obtener la información necesaria, tanto de la arquitectura temprana del Edificio Mayor, como también para poder realizar la correlación morfológico-arquitectónica con el Edificio Menor.

El subsector Edificio Menor es característico porque la superficie irregular de un montículo natural fue acondicionado por medio de rellenos de piedras grandes, arena gruesa y piedrecillas, con muros de contención, delimitando un área aproximada de 17 x $15 \mathrm{~m}$. En su lado Sur se aprecian algunas terrazas de acceso hacia el recinto principal que es de planta cuadrangular con esquinas redondeadas $(7 \times 6,60 \mathrm{~m})$, el cual posee un espacio cuadrangular hundido al interior $(3,30 \times 3,20 \mathrm{~m})$.

Al centro de éste existe un fogón circular (0,60 m de diámetro) enlucido y delimitado por piedras, el mismo que evidenciaba en su interior tierra compacta grisácea con quemas, posteriormente el fogón fue alterado al colocar el entierro de un infante cuya edad varía entre un año a un año

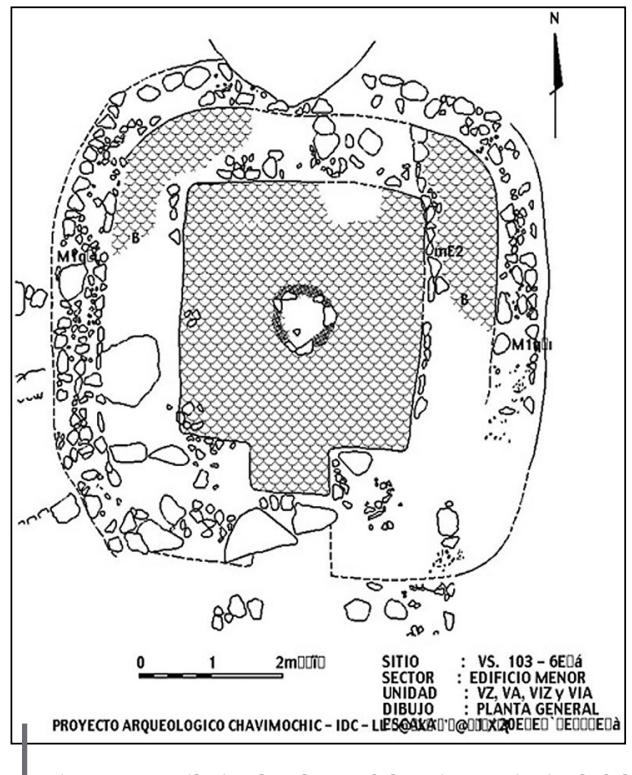

Figura 7 - Dibujo de planta del recinto principal del edificio Precerámico del sector Edificio Menor y medio (análisis antropológico físico del Dr. JeanPaul Lacombe) en posición flexionada decúbito lateral izquierdo, orientado de SW-NE, asociado a material orgánico y un fragmento de cuarzo.

El acceso al recinto principal (figs. 7 y 8 ) del edificio se ubica en el lado sur, a través de un vano de 1,10 $\mathrm{m}$ de ancho. Los muros exteriores $(0,60 \mathrm{~m}$ de ancho) muestran una mampostería de piedra con mortero de barro, un doble paramento, revoque blanquecino como base de $0,08 \mathrm{~m}$ y al cual luego colocarían un enlucido más fino de color gris de $0,04 \mathrm{~m}$ de espesor. El espacio cuadrangular hundido está relacionado a los muros exteriores por medio de banquetas que lo circundan, con un ancho de 0,80 a 1 m, los cuales se elevan a 0,60 m en relación a su piso interior. Las banquetas evidenciaban una fina capa de enlucido amarillento.

El piso más temprano del espacio cuadrangular hundido es de color blanquecino (aunque se observan algunos grumos dispersos de tierra arcillosa grisácea); se encuentra asociado por media caña a los paramentos de las banquetas que lo rodean por sus cuatro lados. Su estado de conservación 


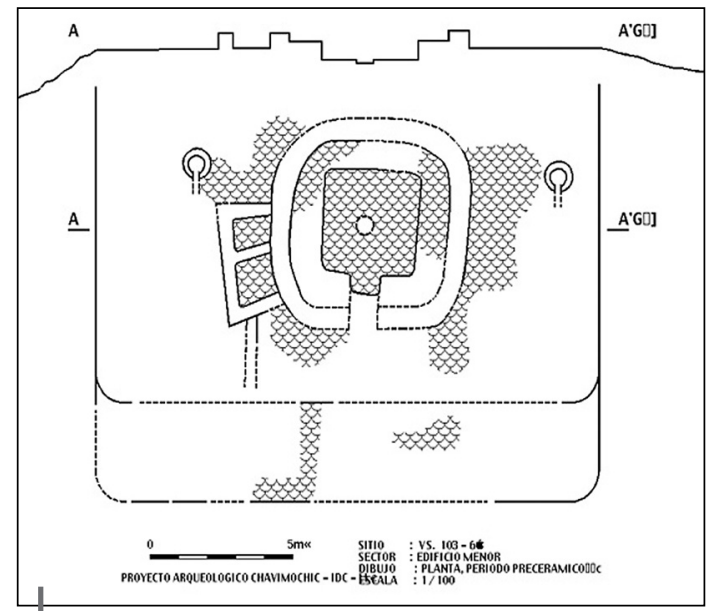

Figura 8 - Dibujo de planta y corte de elevación del edificio Precerámico del sector Edificio Menor no era muy bueno. Un segundo piso se encuentra sobre el anterior y se encuentra aún más deteriorado, es de color amarillento, uniéndose también al revoque blanquecino de los paramentos circundantes de las banquetas. El tercer y último piso presenta una coloración grisácea, se encuentra en buen estado de conservación y también se une por media caña a los paramentos de las banquetas.

Sobre el último piso no se encontró ningún material cultural, solo estaba cubierto por un relleno de $0,20 \mathrm{~m}$ de espesor, compuesto por tierra compacta marrón clara, arena gruesa y piedrecillas, cubriendo íntegramente el espacio cuadrangular hundido. El entierro del infante, por las características estratigráficas, fue colocado primero dentro del fogón y luego fue tapado con piedras pequeñas formando una especie de urna, cubriendo luego exprofesamente todo el espacio cuadrángular hundido con este relleno limpio.

Debemos mencionar que sobre el muro este $(\mathrm{mE} 3)$ de la estructura monumental temprana se halló un hoyo de forma circular, el cual estaba relleno con tierra suelta y arena beige claro; debió ser la impronta de un soporte de techo de esta estructura. En sí las cabeceras de los muros estaban erosionados por lo que no se evidenció mayormente otros postes. De ser así, el poste dejaría entrever que estos muros no debieron ser más altos en relación a la altura conservada.

En la parte exterior del recinto principal, hacia su lado oeste y este, se extiende un piso de color beige (asociado al muro perimetral por media caña). En el lado oeste, y asociado a este piso, se halla un fogón circular de $1 \mathrm{~m}$ de diámetro, delimitado por piedras con argamasa de barro. Hacia el lado este, casi a igual distancia del muro perimetral como del fogón oeste, fue reportado otro fogón circular, de 0,80 m de diámetro, de piedras con mortero de barro, con un ducto de ventilación orientado hacia el sur.

Asociado a una posterior fase constructiva, dentro del mismo periodo Precerámico, se hacen algunos agregados arquitectónicos hacia el lado oeste del recinto principal (estructura cuadrangular con esquinas redondeadas) y se construyen recintos cuadrangulares adosados al muro perimetral externo, directamente sobre el piso. Dos compartimientos forman el recinto con muros de 0,50 m de ancho, de doble paramento hecho de piedras medianas con mortero de barro. Hacia el lado sur se evidencia también una pequeña estructura rectangular de 0,60 x 0,40 m cuyo muro presenta revoque; el piso y revoque de esta estructura evidenciaban manchas rojizas y están sobre el lado noroeste de la primera terraza de acceso (fig. 8)

\section{CORRELACIÓN ARQUITECTÓNICA DE LAS ESTRUCTURAS TEMPRANAS EVIDENCIADAS EN LOS EDIFICIOS MAYOR Y MENOR}

A partir de las características de la arquitectura Precerámica en el Edificio Menor (fig. 9) queremos hacer una comparación con el Edificio Mayor (excavado por otros miembros del PRACH, el cual reportaba similar morfología arquitectónica pero de dimensiones mayores), con la finalidad de establecer semejanzas o diferencias y poder así determinar posibles asociaciones de contemporaneidad y funcionalidad entre ambos edificios precerámicos.

Primeramente describiremos la morfología arquitectónica del recinto principal que se presenta tanto en el Edificio Mayor (fig. 10) como en el Menor; luego se presentarán los elementos o 

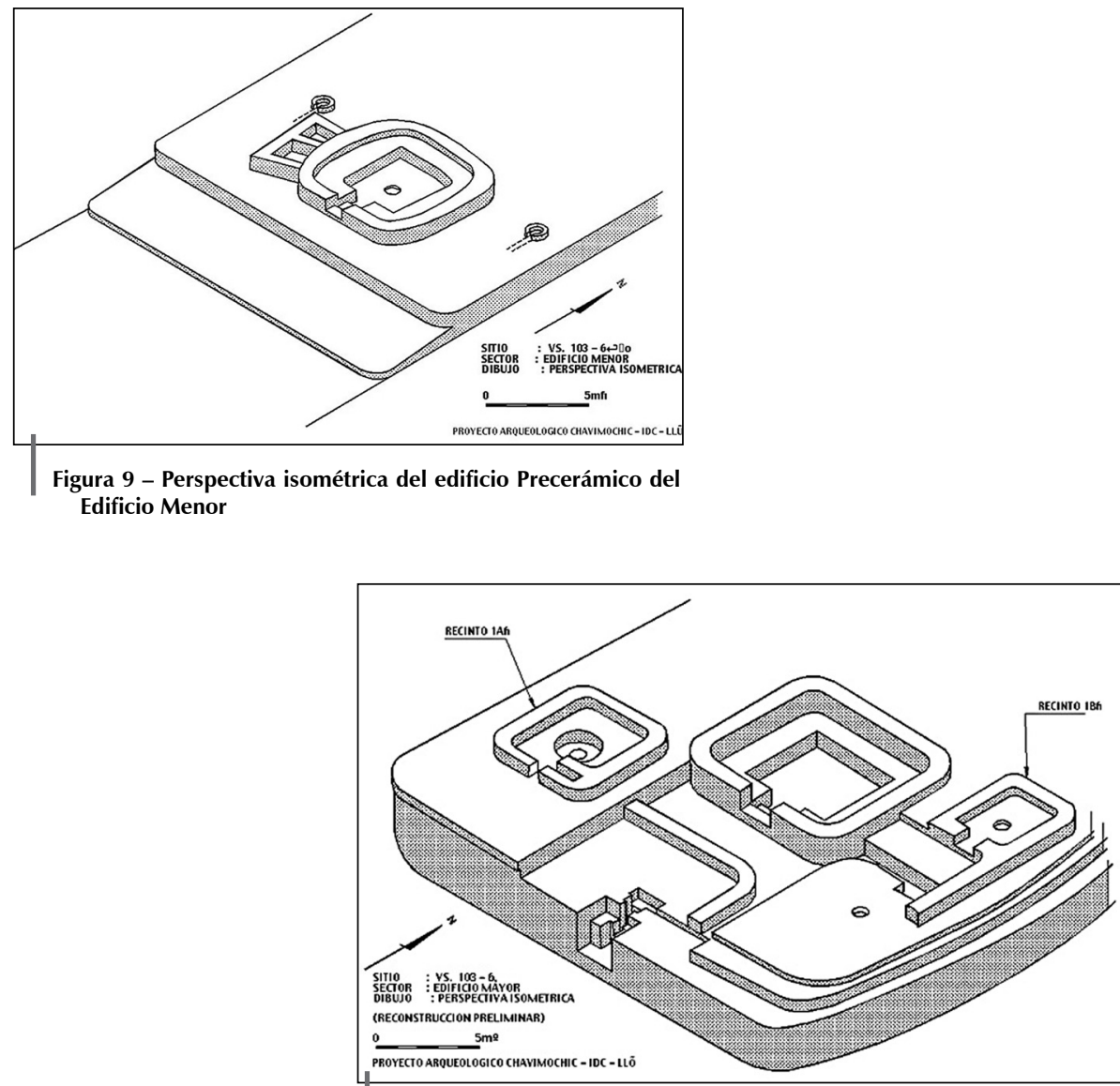

Figura 10 - Perspectiva isométrica del edificio Precerámico del Edificio Mayor

rasgos arquitectónicos inherentes a cada recinto principal, para posteriormente asociarlo a otros elementos y recintos arquitectónicos que se presentan también en ambos edificios.

\section{1. Recintos a doble nivel}

\section{1. 1. Morfología}

Tanto en el Edificio Mayor como en el Menor, el recinto principal se presenta como una estructura arquitectónica cuyos muros perimetrales dan forma a un recinto de planta cuadrada con esquinas redondeadas. Los muros son de doble paramento hechos de piedras medianas con mortero de barro y relleno interno de piedrecillas y barro. Cuatro banquetas se adosan al paramento interno del muro perimetral, dando origen a un espacio cuadrangular hundido al centro del cual se halla un fogón circular (este elemento solo se presenta para el Edificio Menor);el acceso a estos recintos se halla orientado hacia el lado sur. 


\section{1. 2. Elementos arquitectónicos}

Como rasgos o elementos arquitectónicos similares se pueden establecer, en cuanto a forma, los siguientes: muros, pisos a doble nivel, accesos, fogones.

Muros: los muros perimetrales de las estructuras arquitectónicas construidas sobre la plataforma artificial (Edificio Mayor) y el montículo natural (Edificio Menor) dan forma a recintos de planta ligeramente cuadrangular con esquinas redondeadas. Estos muros que, en ambos edificios mantienen una forma y estructura similar, poseen doble paramento hecho de piedras medianas con argamasa de barro y relleno interno de piedrecillas y barro, difiere solo en tamaño. Los muros del recinto principal en el Edificio Mayor tienen un ancho que varía entre 0,70 y 0,90 m y encierran un área de $52 \mathrm{~m}^{2}$ (7,80 $\mathrm{m}$ de este a oeste por 6,70 de norte a sur). En el Edificio Menor los muros tienen un ancho entre 0,60 y 0,75 $\mathrm{m}$ y encierran un área de $46 \mathrm{~m}^{2}$ (7 $\mathrm{m}$ de este a oeste por 6,60 $\mathrm{m}$ de norte a sur). Los muros perimetrales en ambos edificios presentan un revoque tanto exterior como interior, este revoque es de tierra blanquecina y de consistencia tosca que sería una base con revoque grueso de 0,08 m, sobre el cual se colocó un revoque más fino de color gris.

Pisos a doble nivel: presenta la conjunción de varios elementos, está constituido por banquetas, espacio cuadrangular hundido, piso. En ambos edificios se observa (en el área que encierran los muro perimetrales) espacios cuadrangulares hundidos que son resultado del adosamiento de banquetas hacia los lados de los muros, encerrando así un área cuadrangular interna formando un piso a doble nivel.

En El Edificio Mayor las banquetas de los lados este y oeste tienen un ancho de 1,20 m, y $1 \mathrm{~m}$ la de los lados norte y sur, a un desnivel del piso de unos 0,65 m. El espacio cuadrangular interno tiene un área de $14 \mathrm{~m}^{2}$ (4,20 $\mathrm{m}$ de oeste a este por 3,40 $\mathrm{m}$ de norte a sur). En el Edificio Menor las banquetas este y oeste tienen un ancho de $1 \mathrm{~m}$ y las del norte y sur 0,95 $\mathrm{m}$; el desnivel con el piso es de 0,60 m de altura, el espacio cuadrangular interno tiene un área de $10 \mathrm{~m}^{2}$ (3,25 m de norte a sur por 3,30 m de este a oeste). Al parecer toda esta estructura estaba revestida por enlucido fino de color amarillento de aproximadamente $2 \mathrm{~cm}$ de espesor.

Accesos: los vanos de entrada en ambos Edificios están ubicados y orientados hacia el lado sur de la estructura. El Edificio Mayor presenta un ancho de 1,50 m evidenciándose dos escalinatas o peldaños con un contrapaso de 0,35 m aproximadamente. En el Edificio Menor el vano tiene un ancho de 1,10 m, no habiéndose conservado en mayor grado las posibles escalinatas, por efecto de la erosión que afectó en mayor grado ese lado del recinto.

Fogones: Este elemento no se encuentra presente al interno del recinto del Edificio Mayor, en el Edificio Menor se encuentra un fogón ubicado al centro cortando el piso del espacio cuadrangular interno. Tiene un diámetro de 0,60 m y delimitado por piedras medianas.

\section{RASGOS ARQUITECTÓNICOS EN RECINTOS ASOCIADOS AL RECINTO PRINCIPAL A DOBLE NIVEL}

Para la parte externa del recinto principal del Edificio Mayor (fig. 10) se evidencia una mayor complejidad de estructuras con respecto al Edificio Menor (fig. 9), dentro de lo que se considera como la primera fase de construcción en ambos edificios, distinguiéndose los siguientes elementos arquitectónicos:

\section{1. Muros}

En el Edificio Mayor se distinguen dos recintos, ubicados en la parte exterior del recinto principal (al lado norcentral) sobre la plataforma original. Al lado suroeste sobre la terraza se ubica el recinto $1 \mathrm{~A}$ cuyos muros de doble paramento con relleno interno de piedrecillas, tiene un ancho 
de $0,70 \mathrm{~m}$, formando un recinto cuadrangular con esquinas redondeadas de $22,50 \mathrm{~m}^{2}(4,50$ x $5 \mathrm{~m}$ ). El recinto $1 \mathrm{~B}$ se ubica sobre la terraza del lado noreste, sus muros tienen un ancho de $0,70 \mathrm{~m}$ y forman un recinto cuadrangular de menor tamaño con esquinas redondeadas encerrando un área de $13,60 \mathrm{~m}^{2}(3,40 \times 4 \mathrm{~m})$.

\section{2. Pisos}

En el Edificio Mayor se observa un piso que se extiende hacia el lado sur (delante del recinto principal norcentral). Este piso presenta una zona dividida por un muro que forma una especie de antesala. En el Edificio Menor se observan pisos que se extienden hacia el lado oeste del recinto principal presentando estos una coloración beige grisácea de textura compacta.

\section{3. Terrazas}

Para el Edificio Mayor se encuentran algunas terrazas o plataformas superpuestas sobre las que se construyeron algunos recintos: en la plataforma oeste se halla el recinto $1 \mathrm{~A}$, en las plataformas superpuestas al noroeste, de menor tamaño, está el recinto $1 \mathrm{~B}$ y al sur de este recinto se hallan también dos plataformas superpuestas, con un fogón al aire libre, que correspondería a la terraza sureste.

En el Edificio Menor se hallan dos terrazas o plataformas hacia el lado sur, pero estos son de acceso hacia el recinto principal, presentan un desnivel de 0,60 m entre ambas terrazas separadas por muros de contención.

\section{4. Fogones}

\section{4. 1. En el Edificio Mayor}

Se observa una mayor variedad morfológica de los fogones con respecto a su asociación con los recintos, pudiendo precisarse los siguientes tipos:

Fogones dentro de recintos

- Fogón en pozo circular: ubicado al suroeste (al centro del recinto 1 A): el fogón de forma circular corta el piso, el cual a su vez se halla al centro de un pozo circular hundido, este último tiene un diámetro de 1,70 m y el del fogón es de 0,60 m (fig. 10).

- Fogón con ducto de ventilación: ubicado al noroeste (al centro del recinto 1 B): el fogón corta el piso pero se halla delimitado por piedras medianas con argamasa de barro, sobresaliendo esta delimitación sobre el nivel del piso del recinto $1 \mathrm{~B}$. Su forma es circular pero con un ducto de ventilación orientado hacia el sur; tiene un diámetro de 0,80 m.

Fogones al aire libre

Solo se halló un fogón, siendo ubicado al lado sureste sobre la terraza, es de forma circular cortando el piso y tiene un diámetro de $0,50 \mathrm{~m}$ aproximadamente.

\section{4. 2. En el Edificio Menor}

Se puede decir que presenta dos de los tipos registrados para el Edificio Mayor pero estos con particularidades propias:

Fogones al aire libre

- Hacia el lado oeste se halla un fogón circular que corta el piso y es delimitado por piedras medianas con argamasa de barro, sobresaliendo del nivel del piso, tiene un diámetro de $1 \mathrm{~m}$. 
- Hacia el este se halla un fogón parecido al del Edifico Mayor, en la medida en que presentan ambos un ducto de ventilación orientado al sur pero no estando dentro de algún recinto. El fogón que corta el piso es circular, hecho de piedras medianas con argamasa de barro, tiene un diámetro de $0,80 \mathrm{~m}$.

\section{5. Accesos}

En los recintos $1 \mathrm{~A}$ y $1 \mathrm{~B}$ del Edificio Mayor los accesos están orientados hacia el lado sur; el primero tiene un ancho de $0,40 \mathrm{~m}$ y el segundo $0,80 \mathrm{~m}$, presentando un pequeño desnivel en el umbral.

A manera general, una característica particular que se debe tener en cuenta es que el Edificio Mayor consiste en una plataforma artificial que se eleva a más de $2 \mathrm{~m}$ y cuyos lados miden $20 \mathrm{x}$ $14 \mathrm{~m}$, formando una estructura rectangular con esquinas redondeadas, cuyos muros perimetrales hecho de piedras grandes con argamasa de barro, presentaba un revoque beige amarillento y un voladizo o cornisa en la parte superior del muro, con un ancho aproximado de 0,10 m. El acceso a la plataforma se hacía por medio de escalinatas que se ubicaban en su lado sur.

El Edificio Menor se halla sobre un montículo natural, el cual ha sido acondicionado por medio de terrazas de nivelación cuyos lados miden aproximadamente $17 \times 15 \mathrm{~m}$, sobre las cuales se edificó hacia el lado norcentral el recinto principal temprano del Edificio.

En una segunda fase de construcción se producen ampliaciones o se adicionan nuevos recintos, pudiendo ser que esta fase de remodelaciones sea contemporánea en ambos edificios. La remodelación se presenta en mayor grado en el Edificio Mayor que en el Menor, siendo que en el primero a manera general, se amplía la plataforma base hacia el oeste, construyen nuevos recintos con fogón, luego de sellar los anteriores; se varía el acceso. En el Edificio Menor la remodelación se presenta con menos notoriedad ya que se construye un solo recinto sobre el piso (el cual no evidencia acceso) y que se adosa al muro perimetral suroeste del recinto principal.

\section{CORRELACIÓN MORFOLÓGICA ENTRE LOS EDIFICIOS TEMPRANOS}

En general, por las dimensiones de ambos edificios se puede considerar que el Edificio Mayor presenta características monumentales. Eso se debe a la plataforma base de forma rectangular que fue construida sobre el terreno natural, elevándose artificialmente a más de 2 metros de altura. Sobre esta edificarían como recinto principal un recinto de forma cuadrangular con esquinas redondeadas, en cuyo interior se halla un espacio cuadrangular hundido. No presenta fogón y el acceso está orientado hacia el lado sur. El recinto internamente presentaba revoque y estaba enlucido con una fina capa amarillenta. Se reportaron la existencia de fogones en la parte externa de este recinto, uno hacia el suroeste, y siempre sobre la plataforma base, construyéndose un recinto lateral de menor tamaño con pozo hundido y fogón central. Lo mismo se ve hacia el lado noreste: se construyó un recinto conteniendo un fogón central con ducto de ventilación orientado hacia el sur.

La monumentalidad de este edificio con respecto al Edificio Menor se da tanto en lo referente a dimensiones de los rasgos arquitectónicos (que por lo general son morfológicamente similares a ambos edificios), como también por la variedad morfológica que presenta el Edificio Mayor. Este último evidencia rasgos arquitectónicos algo más complejos. En efecto si el recinto principal en el Edificio Mayor no está asociado a un fogón, rasgo que sí se evidencia en el recinto principal del Edificio Menor, la complejidad mayor se encuentra en los fogones que se ubican al exterior del recinto principal del Edificio Mayor donde éstos se encuentran al interior de recintos, a diferencia de los fogones al exterior del recinto principal en el edificio Menor que se encuentran 
al aire libre. También en el Edificio Mayor se presentan algunos aterrazamientos o plataformas superpuestas sobre la plataforma base. El Edificio Menor presenta rasgos arquitectónicos de menor complejidad y dimensión con respecto a los que presenta el Edificio Mayor, aunque morfológicamente los elementos arquitectónicos pueden considerarse comunes a ambos.

La evidencia de una segunda fase constructiva en los Edificios Mayor y Menor (ya sea si se considera contemporáneas o a fases sucesivas de evolución arquitectónica y social), que implicó a su vez ampliaciones arquitectónicas, nuevos recintos, aterrazamientos, etc. nos plantea que estas debieron surgir por modificaciones de determinados conceptos o parámetros originales en los cuales se basaron para edificar en la fase temprana en ambos Edificios y con características particulares. A pesar de los cambios en la estructura original o más temprana (primera fase), se evidencia un patrón de continuidad entre ambas fases constructivas.

\section{COMENTARIOS}

Las estructuras arquitectónicas monumentales asociadas a ocupación del Precerámico Tardío en el sitio El Silencio, son de evidente función ceremonial, en las cuales las actividades rituales estarían centralizadas en los fogones, donde debieron haberse incinerado ofrendas u ofrecer sacrificios, reflejando a su vez el sistema ideológico y religioso de la gente de este periodo. Sin embargo, a pesar de la amplitud de las excavaciones que realizó el PRACH en cuanto a las primeras evidencias de ocupación en el sitio de estudio, no hay mayores datos sobre la gente que debió construir estos edificios. Probablemente vivirían cerca pero de manera estacional o en partes algo alejadas del sitio, las mismas que debieron haber afluido a este centro ceremonial.

La importancia de los edificios tempranos tanto del Mayor como del Menor estaría dada por la inversión de trabajo en cada uno de ellos. Desde un primer momento se elige un nivel de tierra natural para construir el Edificio Mayor. El hecho de construir sobre ella una plataforma base implica un mayor esfuerzo humano. Si consideramos que el Edificio Menor se halla sobre un montículo natural, el cual fue aprovechado como tal y acondicionado por medio de terrazas de nivelación con muros de contención (implicando un menor esfuerzo e inversión de trabajo para su construcción y adecuación), eso indica la importancia que estos edificios pudieron haber tenido.

Surgen sin embargo las siguientes interrogantes: ¿funcionaron contemporáneamente el Edificio Menor y el Edificio Mayor? ¿El Edificio Menor perdió su funcionalidad original al construirse el Edificio Mayor? En relación a esto último se puede plantear que el Edificio Menor probablemente funcionaría como una estructura ceremonial destinada a gente de menor jerarquía o rango social en relación a la del Edificio Mayor que presenta una mayor monumentalidad y complejidad. Se puede plantear también, a manera de hipótesis, que el Edificio Menor representaría una fase más temprana (dentro de este mismo periodo Precerámico) con respecto al Edificio Mayor. En este sentido la ocupación Precerámica en el sitio se iniciaría con la construcción del Edificio Menor, el cual por sus propias características no implicó tanto esfuerzo humano, como sí lo refleja el Edificio Mayor, que bien puede representar un desarrollo arquitectónico y por ende evolutivo en las ideas religiosas de la gente de este periodo. Es más probable entonces que, dada la menor monumentalidad del Edificio Menor, éste marque el inicio en la construcción arquitectónica de los templos precerámicos hallados en el sitio.

Algo similar se presenta en La Galgada, donde también se han reportado dos estructuras muy próximas una de la otra. Grieder et al. (1988) proponen que el Edificio más temprano es el de característica más monumental (al que denomina North Mound) en relación al de menor dimensión (South Mound) cuya construcción sería posterior. Sus planteamientos se basan en los resultados de los fechados radiocarbónicos entre ambos edificios.

Para las fases finales de La Galgada, que según fechados (Grieder et al., 1988: 69) corresponderían al Periodo Inicial, el montículo Norte (North Mound) llega a adquirir paulatinamente cierta forma en $U$, es decir forma arquitectónica de influencia costeña, además de la presencia formal de arquitectura costeña por la existencia de un pozo circular hundido en La Galgada. 
El sitio El Silencio presenta un fenómeno algo similar al de La Galgada: el Edificio Mayor llega a adquirir cierta configuración en $\mathrm{U}$, y se da la presencia de un pozo circular hundido.

Las actividades de entierros representan la última fase de la ocupación precerámica en El Silencio. Es probable que paralelo a esto haya tenido una última actividad ritual que bien puede estar representada por el hallazgo del entierro de un párvulo dentro del fogón central del Edificio Menor; luego de esto se colocaría un relleno exprofeso. Estos hallazgos hacen surgir nuevas interrogantes ¿Representaría tanto el entierro humano en el fogón central como el relleno, un ritual relacionado a la pérdida de función del Edificio Menor? ¿Los sucesivos entierros humanos en el Edificio Menor fueron colocados cuando el edificio Mayor se hallaba en funcionamiento?, o ¿Probablemente marcaría también el final del funcionamiento de esta estructura Mayor? Las evidencias y asociaciones descritas en el presente artículo dan paso a una serie de interrogantes que deberemos esclarecer en futuros trabajos, si es que este tipo de asociaciones entre una estructura monumental de una época Precerámica y la posterior pérdida de su funcionalidad en el marco de rituales de entierros y rellenos exprofesos de las estructuras arquitectónicas constituyen un patrón relacionado a este acontecimiento.

Si es que aceptamos como correcta la evolución planteada por Bonnier para la Tradición Mito, estaríamos ante una difusión de la misma hacia esta parte del valle del Santa, solo en la medida en que no hemos reportado a la fecha edificios Precerámicos del periodo Pre-Mito en el sitio El Silencio.

En este sentido existiría continuidad cultural en otros sitios Precerámicos de la Tradición Mito, lo cual podría estar indicando en esas áreas el origen de esta tradición, por lo que podríamos pensar entonces que efectivamente el sitio El Silencio es resultado de una difusión, que a la fecha, sería la evidencia ubicada más hacia el noroccidente de la religión Mito en los Andes Centrales.

Otra discusión pendiente en lo que respecta al sitio El Silencio, es la presencia (aparte de las estructuras arquitectónicas asimiladas a la Tradición Mito) de una estructura monumental de planta circular de $18 \mathrm{~m}$ de diámetro delimitando un patio circular hundido con un desnivel de $2 \mathrm{~m}$ desde la cabecera del muro que delimita el pozo (fig. 3), la misma que fue hallada aproximadamente a solo $80 \mathrm{~m}$ de distancia hacia el noreste del Edificio Menor. En este sentido, surge la problemática en el sitio El Silencio en relación a la presencia de esta estructura que es de tradición costeña y las estructuras de la tradición serrana Mito, implicando una área de convergencia de estas dos tradiciones arquitectónicas definidas tradicionalmente para áreas diferentes. Este hallazgo debe ser evaluado al intentar caracterizar ambas tradiciones en los Andes Centrales en las futuras investigaciones sobre este periodo.

\section{CONCLUSIONES}

La ocupación del Precerámico Tardío en el sitio El Silencio está representada por un complejo que presenta dos edificios con arquitectura monumental de carácter publico. Implica que a los alrededores debió haber existido gente relacionada con la construcción del mismo, la cual debió afluir a estos templos, indicándonos funcionalmente cierta congregación en torno a un sitio ceremonial.

La ocupación Precerámica Tardía de El Silencio representa la difusión de la tradición serrana Mito, más occidental en los Andes Centrales.

El sitio refleja a su vez ser punto de convergencia de dos tradiciones arquitectónico-religiosas: la Tradición Mito y la de pozos circulares hundidos, definidas para áreas diferentes. La ubicación geográfica del sitio le confiere características particulares como puerto comercial entre grupos serranos y costeños. Este hecho podría explicar la presencia de estos diferentes estilos arquitectónicos. 


\begin{abstract}
Agradecimientos
Agradezco especialmente tanto a la dirección como al personal del entonces Proyecto de Rescate Arqueológico Chavimochic (PRACH): Dr. Santiago Uceda C., así como a los licenciados arqueólogos José Carcelén Silva, Víctor Peña Huamán, César Santos, Víctor Pimentel Spissu, Elena Goycochea, Rosa Marín Jave, Lorena Zuñiga, al dibujante Galo Sisniegas, así como al personal auxiliar, quienes intervinieron en las temporadas de campo y gabinete de los años 1988-1989 en el valle del Santa. Agradezco también de manera muy especial al Dr. D. Bonavia, al Arqto. J. Canziani, a la Lic. A. Wong y a la Dra. E. Bonnier, quienes colaboraron amablemente con sus críticas y sugerencias para dar a conocer el presente artículo.
\end{abstract}

\title{
Referencias citadas
}

BIRD, J., 1948 - Preceramic Cultures in Chicama and Viru. In: A Reappraisal of Peruvian Archaeology (Bennett, W. C. (ed.): 21-28. Suplemento de American Antiquity, 13 (4/2). Memoirs of the Society for American Archaeology 4; Salt Lake City.

BONAVIA, D., 1994 - Perú, Hombre e Historia. De los Orígenes al siglo XV. Tomo I, 586 p.; Lima: EDUBANCO. 1a edición.

BONNIER, E., 1997 - Preceramic Architecture in the Andes: The Mito Tradition. In: Archaeologica Peruana 2. Prehispanic Architecture and Civilization in the Andes (E. Bonnier \& H. Bischof, eds.): 120-144; Sociedad Arqueológica Peruano-Alemana. Reiss-Museum Mannheim.

BONNIER, E. \& ROZEMBERG, C., 1987 - El Proyecto Tantamayo Piruru, Arqueología en un valle del Alto Marañón. Revista Kuntur, n 3: 2-9; Lima.

BURGER, R. \& SALAZAR BURGER, L., 1980 - Ritual and Religion at Huaricoto. Archaeology, $\mathbf{n}^{\circ} 33$ (6): 26-32; New York.

FUNG, R., 1988 - The Late Preceramic and Initial Period Peruvian Prehistory. In: Peruvian Prehistory-An Overview of Pre-Inca and Inca Society (Richard W. Keatinge, ed.): 67-96; Cambridge: Cambridge University Press.

GRIEDER, T., BUENO, A., SMITH, E. \& MALINA, R., 1988 - La Galgada, Peru. A Preceramic Culture in Transition, 282 p.; Austin: University of Texas Press.

IZUMI, S. \& TERADA, K. (eds.), 1972 - Andes 4: Excavations at Kotosh, Peru, 1963 and 1966, 375 p.; Tokio: University of Tokio Press.

LUMBRERAS, L. G., 1981 - Arqueología de la América Andina, 278 p.; Lima: Editorial Milla Batres.

MONTOYA VERA, M. del R., 1989 - Estudio preliminar sobre uso del espacio en un asentamiento Recuay, y secuencia ocupacional. Sitio VS-103:6. Quebrada El Silencio. Valle Medio del Santa. Tesis para obtener grado de Bachiller en Ciencias Sociales. Escuela Académico Profesional de Arqueología. Facultad de Ciencias Sociales. Universidad Nacional de Trujillo.

ONERN, 1972 - Cuencas de los Ríos Santa, Lacramarca y Nepeña. Inventario, Evaluación y Uso Racional de los Recursos Naturales de la Costa; Lima.

POZORSKI, T. \& POZORSKI, S., 1999 - Una reevaluación del desarrollo de la sociedad compleja durante el Precerámico Tardío en base a los fechados radiocarbónicos y a las investigaciones arqueológicas en el valle de Casma. Boletín de Arqueología PUCP, $\mathrm{n}^{\circ}$ 3. El Periodo Arcaico en el Perú: Hacia una definición de los orígenes: 171-186; Lima: Pontificia Universidad Católica del Perú.

UCEDA, S., CARCELÉN, J., DEZA, C. \& SALINAS, M., 1988 - Catastro de los sitios arqueológicos del área de influencia del canal de irrigación Chavimochic: Valles de Santa y Chao. Serie Patrimonio Arqueológico de la Zona Norte 1. Instituto Departamental de Cultura-La Libertad. 


\section{FE DE ERRATA}

Bulletin de l'Institut Français d'Études Andines / 2007, 36 (1)

En la página 162 se lee lo siguiente: «Se sintetizan y se verifican estas dos tendencias en la elección de junio de 2006. Sin los votos de Lima, Alejandro Toledo no habría llegado a ser presidente de la República peruana».

Debería decir: «Se sintetizan y se verifican estas dos tendencias en la elección de junio de 2006. Sin los votos de Lima, Alan García no habría llegado a ser presidente de la República peruana». 